\title{
Changes in phasic femoral artery flow induced by various stimuli: a study with percutaneous pulsed Doppler ultrasound ${ }^{1}$
}

\author{
F. MAHLER ${ }^{2}$, H. H. BRUNNER, A. BOLLINGER, M. CASTY, AND \\ M. ANLIKER \\ From the Department of Internal Medicine, and Institute of Biomedical Engineering, \\ University of Zurich
}

SUMMARY Transcutaneous blood flow measurements were performed by means of a pulsed Doppler ultrasound flowmeter in the femoral artery of healthy subjects. The pulsatile flow pattern was changed characteristically from resting state by postocclusive reactive hyperaemia, by the application of amyl nitrite, xanthinol nicotinate, and angiotensin amide. During reactive hyperaemia systolic flow was increased, diastolic reverse flow was abolished, and the forward flow continued throughout diastole. Amyl nitrite augmented the negative flow phase and reduced mean flow, while xanthinol nicotinate decreased the negative component and augmented mean flow. Angiotensin amide produced enhancement of the average flow by elevating systolic and diastolic flow equally over the base line. In each of these interventions the changes in flow were determined mainly by variations during the diastolic flow phase.

Noninvasive measurements of mean blood flow in segments of the upper and lower extremities were performed for many years in human physiology as well as in clinical routine using venous occlusion plethysmography (Hillestad, 1963; Bollinger, 1969; Whelan, 1967). After the introduction of ultrasonic flow detectors, the way was opened for noninvasive evaluation of the flow velocity in individual vessels of medium and larger size of the extremities and the neck (Strandness et al., 1966; Bernstein et al., 1970; Fronek et al., 1973a; Fronek et al., 1973b; Yao and Bergan, 1974). However, quantitative measurements of flow in single arteries were not feasible until recently, when pulsed multichannel Doppler ultrasound devices were developed. These instruments allow the detection of flow velocity profiles in arteries with sufficient spatial and temporal resolution to compute volume flow by integrating the velocity profiles over the cross-sectional area of the vessel (Brunner et al., 1974; McLeod, 1974; Doriot et al., 1975). Since the common femoral artery is well suited for the application of this technique by

${ }^{1}$ Presented in part at the annual meeting of the German Society of Angiology, 1975, Cologne, GFR.

${ }^{2}$ Address for correspondence and reprints: Dr F. Mahler, Department of Internal Medicine, Inselspital, CH-3010 Bern, Switzerland. its size and superficial location, it was chosen to study the influence of regional and systemic changes in vascular resistance upon pulsatile flow into the leg in a group of healthy volunteers.

\section{Methods}

Measurements were performed in 9 healthy subjects ( 8 males, 1 female, age ranging from 21 to 35 years, mean 24.0 years). The subjects rested in supine position for $20 \mathrm{~min}$ before they were studied. After resting values were registered, the circulation to the lower limb was arrested by inflation of a cuff around the thigh above the knee joint for $3 \mathrm{~min}$ to produce postocclusive reactive hyperaemia (PORH). As second intervention, amyl nitrate was given to the subjects for inhalation during 2 deep breaths. Then a cubital vein was punctured and angiotensin amide applied intravenously in a rate of 0.2 to $1.0 \mu \mathrm{g} / \mathrm{min}$ until mean arm pressure ([ $2 \times$ diastolic $+1 \times$ diastolic pressure]/3) was increased by about $3 \mathrm{kPa}$ (20 $\mathrm{mmHg}$ ). To prevent marked bradycardia during the pressure elevation, which was seen in some subjects, atropine $(0.5$ to $0.8 \mathrm{mg})$ was injected in 4 cases. After return to the basic pressure values, xanthinol nicotinate (Complamin $\otimes$ ) was applied intravenously to 6 subjects in doses between 75 and 
$150 \mathrm{mg}$. The effect of this last drug was followed for $15 \mathrm{~min}$ before the experiments were terminated.

For the percutaneous measurement of the volume flow in the common femoral artery a recently developed multichannel pulsed Doppler velocity meter was used (Doriot et al., 1975). In brief, ultrasound $(7 \mathrm{MHz})$ is emitted with a pulse repetition rate of 12 to $15 \mathrm{kHz}$, and the reflected ultrasonic waves are sampled in 14 gates whose total width can be set according to the diameter of the artery under study. The transducer is positioned by a specially designed holder pointing upstream at a fixed angle to the longitudinal axis of the common femoral artery. The vascular diameter is determined with the transducer at right angles to the arterial axis, where maximum echo signals from the wall are received, while the Doppler shift is minimal. This position serves also as reference for assessing the angle of the transducer to the vessel during the flow measurements. An integrating circuit adds the velocity profiles from the different gates over the cross sectional area of the vessel, assuming a circular shape and accounting for the angle of inclination, in order to obtain the total instantaneous flow in the vessel. An additional circuit with a time constant of $3.5 \mathrm{~s}$ produces an average signal of the phasic output (Doriot et al., 1975). The accuracy of the pulsed Doppler-flowmeter was evaluated in a bench model, where deviations from real flow volume by $\pm 5 \%$ were observed (Doriot et al., 1975). An animal model was developed simulating the transcutaneous application of the ultrasonic flowmeter in human subjects (Rutishauser et al., 1974). Simultaneous measurements of the aortic flow in dogs were performed using electromagnetic flowmeter cuffs applied directly to the aorta and Doppler ultrasound across a layer of skin and subcutaneous adipose tissue interposed between the vessel and the transducer. The directly and transcutaneously measured values differed in the average by $25 \%$, since deviations of the transducer from the longitudinal axis, errors in determining the inclination, and the vessel diameter are difficult to avoid completely. For application in human subjects the same sources of error may be effective. However, in the present study, comparisons were made only between values obtained in single individuals, in whom position of the transducer and the setting of the gates remained unchanged during the experiments, and therefore inaccuracies in absolute figures do not play a substantial role in the observation of the induced responses. As mentioned, the diameter was assessed in control state and left unchanged during the interventions, and assumed that the variations in flow were produced by variations in velocity rather than by changes in diameter. Small cross-sectional variations, which could have occurred because of the interventions and the pressure pulsations are compensated to some extent in our method of determining the volume flow rate (Doriot et al., 1975). Besides this, major deviations from the control diameter would have been noticed from the oscilloscope recordings of the spatial velocity profiles.

The following values were analysed from the phasic flow tracings: systolic maximum flow $\left(Q_{\max }\right)$, diastolic minimum flow $\left(\dot{Q}_{\mathrm{m} \ln }\right)$, the flow pulse amplitude $\left(Q_{\max }-\dot{Q}_{\min }=\Delta Q\right)$ and mean flow (mean $Q$ ) from the average signal. Recordings were made throughout the experiments with a paper speed of $1-2 \mathrm{~mm} / \mathrm{s}$ and $25-50 \mathrm{~mm} / \mathrm{s}$ during the interventions (Gould Brush, Model 480 with 2 wide channels). Arm artery pressures were determined by cuffs using Korotkoff sounds. For statistical comparisons, a program for paired $t$ test was used (Hewlett-Packard 65).

\section{Results}

Table 1 shows average values with standard deviations from the 9 subjects at rest and during the subsequent interventions. The values were compared statistically with the control values, taken immediately before each single intervention. Fig. 1 indicates how maximum flow $\left(\dot{Q}_{\max }\right)$, minimum flow $\left(\dot{Q}_{m i n}\right)$, and flow amplitude $(\Delta Q)$ were defined and calculated. Fig. 2 illustrates the responses in the phasic flow pattern to the 4 different interventions in the same individual for comparison with Fig. 1.

\section{RESTING STATE}

The typical phasic flow pattern of the common femoral artery is shown in Fig. 1. During resting state the systolic flow wave was always followed by a second component with reverse flow in early diastole and a subsequent positive third component. Average values for $Q_{\max }, Q_{m i n}$, and mean $Q$ are listed in Table 1; the diastolic forward flow wave $(6.0 \pm$ $2.8 \mathrm{~cm}^{3} / \mathrm{s}$ ) amounted to $25 \pm 12 \%$ of the $\dot{Q}_{\max }$ values.

\section{POSTOCCLUSIVE REACTIVE HYPERAEMIA}

The course of the postocclusive reactive hyperaemia (PORH) is shown in a typical example in Fig. 3. During arterial occlusion with a pressure cuff above the knee, $Q_{\max }$ decreased from $25.6 \pm 13.6$ (control) to $19.4 \pm 8.9 \mathrm{~cm}^{3} / \mathrm{s} \quad(P<0.02)$, while $Q_{\mathrm{min}}$ did not change significantly (Table 1). Mean $Q$ declined from $4.4 \pm 1.9$ to $2.1+1.0 \mathrm{~cm}^{3} / \mathrm{s}(\mathrm{P}<0.001)$. After release of the occlusion cuff, the reverse flow phase disappeared, $\mathbf{Q}_{\mathrm{m} \text { in }}$ showed always positive values and was shifted from the early to the late diastole (Fig. 2). $Q_{\max }$ was almost doubled, while $\Delta \dot{Q}$ did not 
Table Effects of different changes in local or systemic flow resistance on femoral flow

\begin{tabular}{|c|c|c|c|c|c|c|c|c|c|c|c|c|c|c|c|c|c|c|}
\hline & & \multicolumn{3}{|c|}{$\begin{array}{l}\dot{Q}_{\max } \\
\left(\mathrm{cm}^{3} / s\right)\end{array}$} & \multicolumn{3}{|c|}{$\begin{array}{l}Q_{\min } \\
\left(\mathrm{cm}^{3} / \mathrm{s}\right)\end{array}$} & \multicolumn{3}{|c|}{$\begin{array}{l}\Delta \dot{Q} \\
\left(\mathrm{~cm}^{3} / \mathrm{s}\right)\end{array}$} & \multicolumn{3}{|c|}{$\begin{array}{l}\text { Mean } \dot{Q} \\
\left(\mathrm{~cm}^{3} / \mathrm{s}\right)\end{array}$} & \multicolumn{2}{|c|}{$\begin{array}{l}H R \\
\left.\left(m^{-1}\right)^{-1}\right)\end{array}$} & \multicolumn{2}{|c|}{$\begin{array}{l}\text { Syst BP } \\
(k P a)\end{array}$} & \multirow{2}{*}{$\begin{array}{l}\text { Diast } B P \\
(k P a) \\
C \quad I\end{array}$} \\
\hline & & $C$ & & $1 \%$ & $C$ & $I$ & $.1 \%$ & $C$ & $I$ & $4 \%$ & $C$ & $I$ & $4 \%$ & & & & & \\
\hline $\begin{array}{l}\text { RH } \\
(\mathrm{n}=9)\end{array}$ & $\begin{array}{l}\bar{x} \\
\text { SD } \\
\text { SE } \\
P\end{array}$ & $\begin{array}{r}25.6 \\
13.6 \\
4.5\end{array}$ & $\begin{array}{r}44.1 \\
19.1 \\
6.4 \\
0.001\end{array}$ & $\begin{array}{r}+84 \\
20 \\
7\end{array}$ & $\begin{array}{r}-11.0 \\
4.6 \\
1.6\end{array}$ & $\begin{array}{r}+13.7 \\
9.4 \\
3.1 \\
0.001\end{array}$ & $\begin{array}{r}218 \\
68 \\
23\end{array}$ & $\begin{array}{r}36.1 \\
17.6 \\
5.9\end{array}$ & $\begin{array}{r}30.4 \\
12.1 \\
4.0 \\
\text { NS }\end{array}$ & $\begin{array}{r}-12 \\
19 \\
7\end{array}$ & $\begin{array}{l}4.4 \\
1.9 \\
0.7\end{array}$ & $\begin{array}{r}25.3 \\
7.3 \\
2.4 \\
0.001\end{array}$ & $\begin{array}{r}505 \\
186 \\
62\end{array}$ & $\begin{array}{r}68.2 \\
7.3 \\
2.4 \\
\mathrm{~N}\end{array}$ & $\begin{array}{r}73.0 \\
11.3 \\
3.8\end{array}$ & $\begin{array}{r}16.0 \\
1.1 \\
0.3\end{array}$ & $\begin{array}{r}16.3 \\
1.1 \\
0.4\end{array}$ & $\begin{array}{rr}10.7 & 11.0 \\
1.1 & 1.1 \\
0.3 & 0.4\end{array}$ \\
\hline $\begin{array}{l}\text { AMT } \\
(n=9)\end{array}$ & $\begin{array}{l}\bar{x} \\
\text { SD } \\
\text { SE } \\
P\end{array}$ & $\begin{array}{r}27.6 \\
13.9 \\
4.6\end{array}$ & $\begin{array}{r}32.7 \\
12.4 \\
4.1 \\
0.02\end{array}$ & $\begin{array}{r}28 \\
28 \\
9\end{array}$ & $\begin{array}{r}-10.1 \\
5.1 \\
1.7\end{array}$ & $\begin{array}{r}-16.1 \\
9.3 \\
3.1 \\
0.05\end{array}$ & $\begin{array}{r}-72 \\
80 \\
27\end{array}$ & $\begin{array}{r}37.7 \\
18.6 \\
6.2\end{array}$ & $\begin{array}{r}51.4 \\
21.9 \\
7.3 \\
0.001\end{array}$ & $\begin{array}{r}+35 \\
29 \\
10\end{array}$ & $\begin{array}{l}4.8 \\
2.0 \\
0.7\end{array}$ & $\begin{array}{c}3.2 \\
3.4 \\
1.1 \\
\mathrm{NS}\end{array}$ & $\begin{array}{r}-33 \\
79 \\
26\end{array}$ & $\begin{array}{c}71.8 \\
14.6 \\
4.9 \\
0.0\end{array}$ & $\begin{array}{r}101.0 \\
19.9 \\
6.6 \\
05\end{array}$ & $\begin{array}{c}16.1 \\
1.3 \\
0.4 \\
0.0\end{array}$ & $\begin{array}{r}13.6 \\
1.6 \\
0.5 \\
001\end{array}$ & $\begin{array}{cc}10.9 & 9.6 \\
1.3 & 2.0 \\
0.4 & 0.7 \\
0.025\end{array}$ \\
\hline $\begin{array}{l}\text { ANG } \\
(n=9)\end{array}$ & $\begin{array}{l}\bar{x} \\
S D \\
S E \\
P\end{array}$ & $\begin{array}{r}26.4 \\
14.3 \\
4.8\end{array}$ & $\begin{array}{r}30.9 \\
15.6 \\
5.2 \\
0.025\end{array}$ & $\begin{array}{r}19 \\
21 \\
7\end{array}$ & $\begin{array}{r}-12.3 \\
7.5 \\
2.5\end{array}$ & $\begin{array}{r}-5.2 \\
6.1 \\
2.0 \\
0.001\end{array}$ & $\begin{array}{r}+71 \\
31 \\
10\end{array}$ & $\begin{array}{r}38.8 \\
21.3 \\
7.1\end{array}$ & $\begin{array}{r}36.4 \\
20.5 \\
6.8 \\
\text { NS }\end{array}$ & $\begin{array}{r}-7 \\
15 \\
5\end{array}$ & $\begin{array}{l}4.8 \\
2.3 \\
0.8\end{array}$ & $\begin{array}{c}9.4 \\
3.5 \\
1.2 \\
0.001\end{array}$ & $\begin{array}{r}113 \\
62 \\
21\end{array}$ & $\begin{array}{r}71.2 \\
15.3 \\
5.1 \\
\mathrm{~N}\end{array}$ & $\begin{array}{r}66.1 \\
13.4 \\
4.5\end{array}$ & $\begin{array}{c}16.1 \\
0.9 \\
0.3 \\
0.0\end{array}$ & $\begin{array}{r}18.7 \\
1.7 \\
0.6 \\
001\end{array}$ & $\begin{array}{cc}10.9 & 13.2 \\
1.3 & 1.9 \\
0.4 & 0.6 \\
0.001\end{array}$ \\
\hline $\begin{array}{l}\text { NIC } \\
(n=6)\end{array}$ & $\begin{array}{l}\hat{x} \\
\text { SD } \\
\text { SE } \\
P\end{array}$ & $\begin{array}{r}25.2 \\
14.8 \\
6.0\end{array}$ & $\begin{array}{l}29.5 \\
16.1 \\
6.6 \\
0.05\end{array}$ & $\begin{array}{l}+16 \\
17 \\
7\end{array}$ & $\begin{array}{r}-10.2 \\
6.4 \\
2.6\end{array}$ & $\begin{array}{r}-5.9 \\
4.0 \\
1.6 \\
0.05\end{array}$ & $\begin{array}{r}+39 \\
35 \\
14\end{array}$ & $\begin{array}{l}35.4 \\
20.9 \\
8.5\end{array}$ & $\begin{array}{r}35.4 \\
18.2 \\
7.4 \\
\mathrm{NS}\end{array}$ & $\begin{array}{c}+6 \\
13 \\
5\end{array}$ & $\begin{array}{l}5.0 \\
2.8 \\
1.1\end{array}$ & $\begin{array}{r}7.8 \\
3.8 \\
1.6 \\
0.02\end{array}$ & $\begin{array}{r}+70 \\
47 \\
19\end{array}$ & $\begin{array}{r}70.8 \\
10.3 \\
4.2 \\
0.0\end{array}$ & $\begin{array}{r}94.0 \\
14.7 \\
6.0 \\
05\end{array}$ & $\begin{array}{r}16.3 \\
1.3 \\
0.5 \\
\text { N }\end{array}$ & $\begin{array}{r}16.5 \\
1.0 \\
0.8 \\
S^{0.8}\end{array}$ & $\begin{array}{rr}10.9 & 10.4 \\
1.4 & 1.6 \\
0.6 & 0.6 \\
\text { NS } & \end{array}$ \\
\hline
\end{tabular}

$\dot{Q}_{\max }=$ maximum (systolic) flow, $\dot{Q}_{\mathrm{n} n \mathrm{n}}=$ minimum (diastolic) flow, $\Delta \dot{Q}=$ flow pulse amplitude, mean $Q=$ mean flow in the femoral artery measured by pulsed Doppler ultrasound. $\mathbf{H}=$ heart rate, $\mathbf{B P}=\mathbf{a r m}$ blood pressure, $\mathbf{C}=$ control values, $\mathbf{I}=$ values induced by the interventions, $J \%=$ percentage change from control, $\mathrm{RH}=$ reactive hyperaemia. AMT =amyl nitrite, ANG $=$ angiotensin amide, NIC $=$ xanthinol nicotinate, $\bar{x}=$ mean values, $S D=$ standard deviation, $S E=$ standard error, $\mathrm{P}=$ significance level, $\mathbf{N} \mathbf{S}=$ not significant, $\mathrm{n}=$ number of subjects.

Conversion: J kPa $=7.519 \mathrm{mmHg}$

vary significantly. The greatest changes occurred in mean $Q$, increasing by multiples of the resting values (average 505$\rfloor 186 \%$ ). Systemic blood pressure and heart rate did not change significantly during PORH (Table 1).

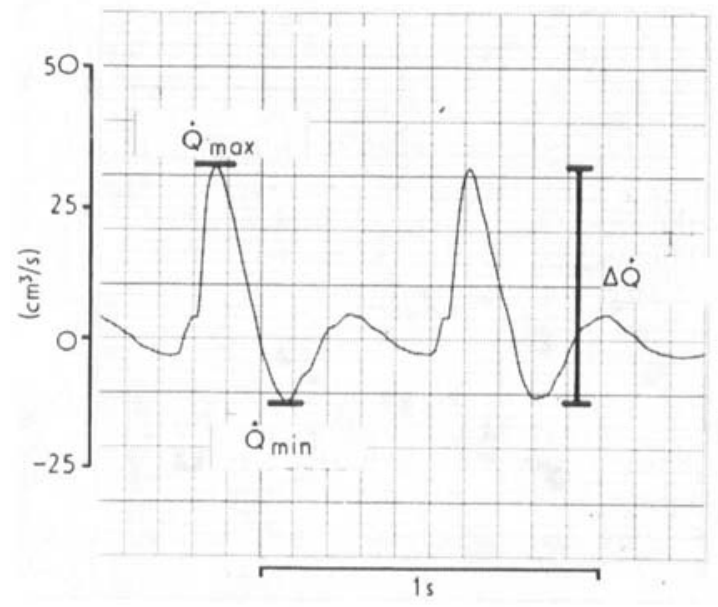

Fig. 1 Pulsatile flow measured transcutaneously by pulsed Doppler flowmerer in common femoral artery of normal subject during resting state. It is indicated, where maximum flow $\left(Q_{m a x}\right)$, minimum flow $\left(Q_{\min }\right)$, and flow pulse amplitude $\left(\dot{Q}_{\max }-\dot{Q}_{\min }=\Delta \dot{Q}\right)$ are measured.
3. AMYL NITRITE

20 to $30 \mathrm{~s}$ after inhalation of this substance, the phasic systolic flow pattern was altered characteristically (Fig. 2). The positive systolic flow wave as well as the reverse flow increased, leading to an augmenta-
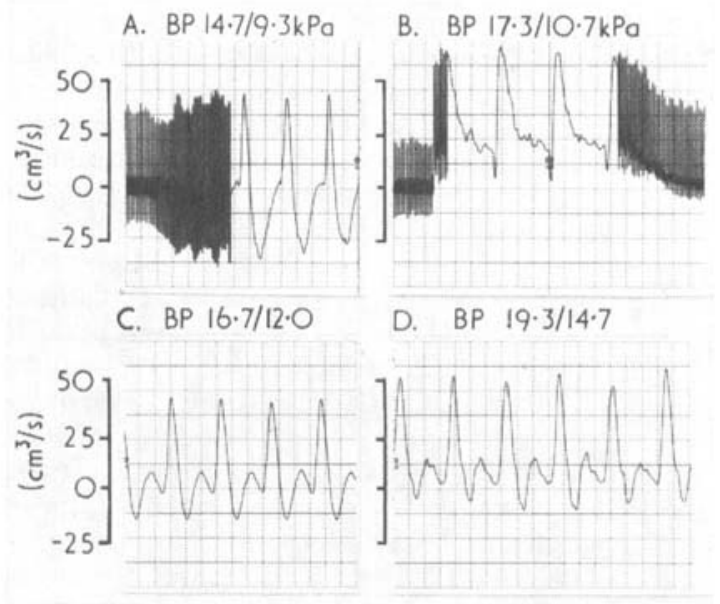

Fig. 2 Effect of different interventions on pulsatile flow in common fenoral artery in same subject as Fig. 1: Panel $A$ amyl nitrite, panel $B$ postocclusive reactive hyperaemia, panel $C$ atropine, panel $D$ angiotensine amide + atropine. $B P=$ blood pressure.

Conversion: $I \mathrm{kPa}=7.519 \mathrm{mmHg}$. 


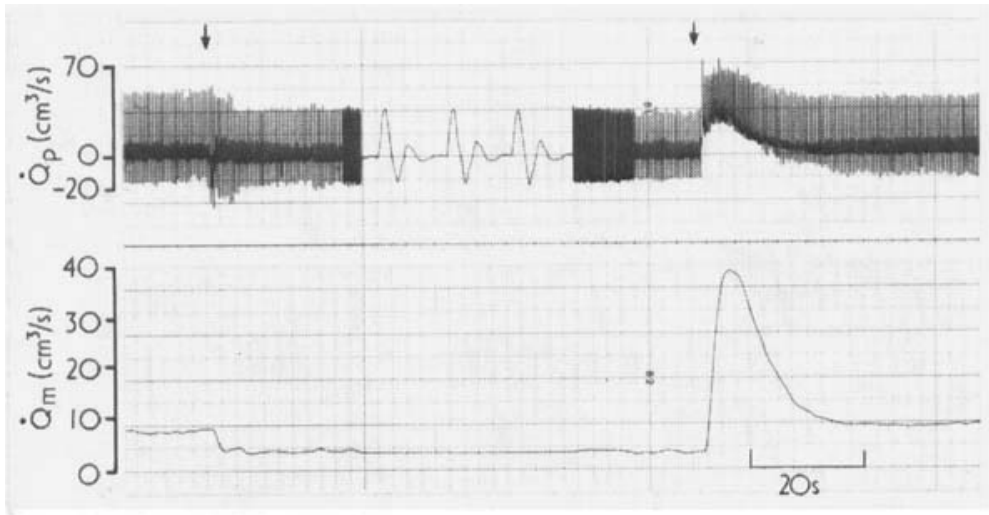

Fig. 3 Original tracings of pulsatile flow $\left(\dot{Q}_{p}\right)$ and mean flow $\left(Q_{m}\right)$ in common femoral artery from pulsed Doppler flowmeter in normal subject, illustrating effect of distal arterial occlusion and postocclusive reactive hyperaemia (arrows).

tion in $\Delta Q$. The positive diastolic flow wave disappeared, and the flow pulse pattern became biphasic. At the peak of the reaction, a significant drop in systemic pressure and a substantially accelerated heart rate were observed. In 2 cases, where heart rate was increased after injection of atropine into comparable ranges, the change in frequency alone did not induce the same alterations in the flow wave pattern as amyl nitrite (Fig. 2), and the normal appearance remained essentially unchanged.

\section{ANGIOTENSIN AMIDE}

Fig. 4 illustrates the reaction in femoral flow to infusion of angiotensin amide. In the average, mean systemic blood pressure was elevated by $2.5 \mathrm{kPa}$ (19 $\mathrm{mmHg}$ ). The appearance of the flow wave form did not differ much from resting state. However, the curve was shifted to a higher level above the zero line. Because of a comparable increase in $\dot{Q}_{\max }$ and $\dot{Q}_{\mathrm{min}}, \Delta Q$ remained unaltered. Mean $Q$ was increased considerably $(P<0.001)$, mainly because the diastolic flow was augmented despite a decrease in heart rate by 5 beats $/ \mathrm{min}$. Calf circumference decreased despite the enhanced inflow volume.

\section{XANTHINOL NICOTINATE}

Slow injection of this drug produced in the average of 6 subjects an increase in $Q_{\max }, Q_{\min }$, and mean $\dot{Q}$, but no change in $\Delta \dot{Q}$. In contrast to the response to angiotensin amide, the positive diastolic flow wave was abolished, and the flow pulse contour resembled that after application of amyl nitrite although the responses in heart rate and blood pressure were different. Unlike amyl nitrite, the negative flow component and the amplitude $\Delta \mathbf{Q}$ was not increased by this compound. Calf circumference diminished during the augmentation of mean flow. An example of this reaction with a marked increase in mean $Q$ is illustrated in Fig. 5.

\section{Discussion}

By means of transcutaneous pulsed Doppler ultrasound, a variety of characteristic pulsatile flow patterns was observed in the common femoral artery after changes in regional or systemic vascular resistance were induced by 4 different interventions. These alterations in the phasic flow were described in terms of maximum systolic flow ( $\left.\dot{Q}_{\max }\right)$, minimum

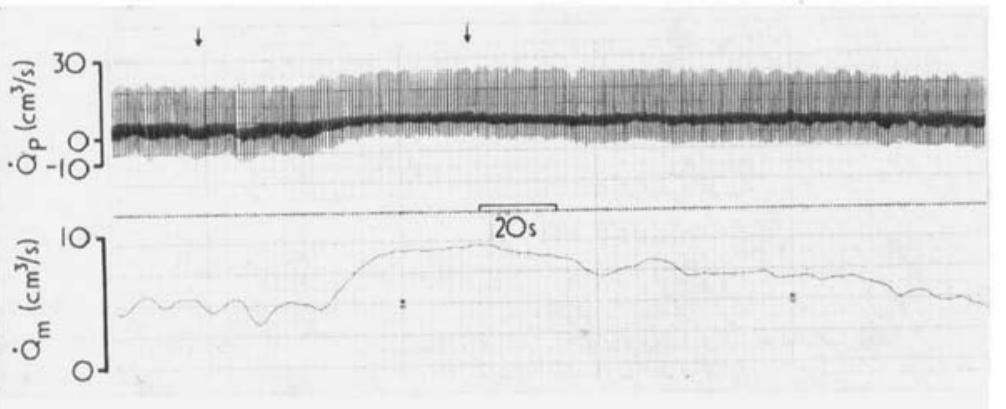

Fig. 4 Effect of short infusion of angiolensin amide (between arrows) on phasic $\left(\dot{Q}_{p}\right)$ and mean $\left(\dot{Q}_{m}\right)$ Doppler flow in common femoral artery of normal subject. Arm blood pressure was elevated from $16.09 .3 \mathrm{kPa}(120,70 \mathrm{mmHg})$ (control) to $18.0 / 10.0 \mathrm{kPa}$ $(135 / 75 \mathrm{mmHg})$ at peak of reaction. 


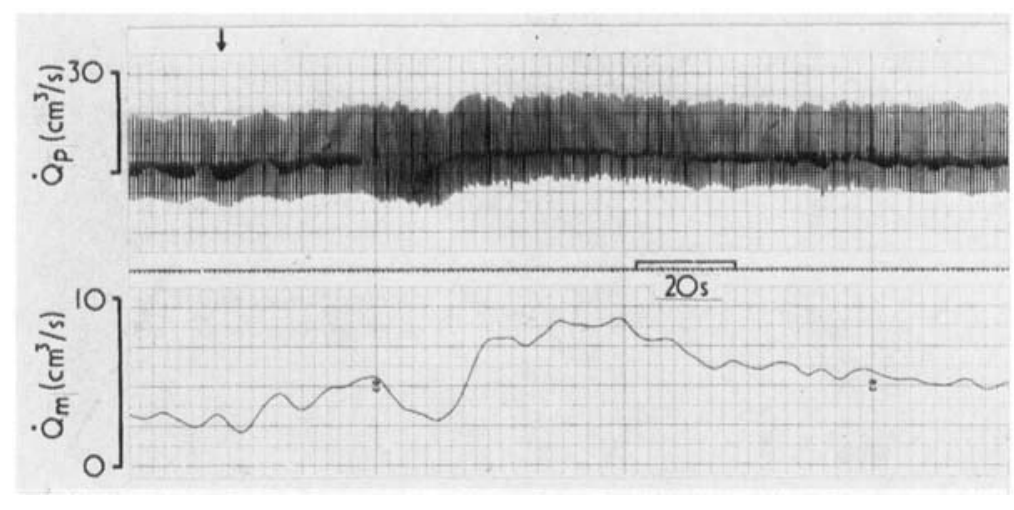

Fig. 5 Phasic $\left(\dot{Q}_{p}\right)$ and mean $\left(\dot{Q}_{m}\right)$ Doppler flow in common femoral artery of normal subject during injection of xanthinol nicotinate (arrow).

flow ( $Q_{\mathrm{min}}$ ) occurring in early diastole in resting state, and the flow wave amplitude $(\Delta Q)$.

Reactive hyperaemia after a standardised period of circulatory arrest (PORH) is a representative intervention to lower regional resistance in the extremities without substantial changes of the systemic circulation (Hillestad, 1963; Zelis and Mason, 1970). It has been described in connection with continuous wave ultrasonic velocity measurements for testing the functional reserves of arterial flow capacity in normal subjects, in athletes, and in patients with peripheral arterial occlusive disease (Fronek et al., 1973a; Fronek et al., 1973b; Mahler et al., 1976). Eecause of the different site and duration of the occlusion and probably also of technical differences in the ultrasonic devices, the increase in mean $Q$ of $505 \%$ over the resting flow exceeds considerably the values given in these previous papers. However, in all of the studies, this increment in mean $Q$ is found to be a multiple of the resting flow value using both continuous wave and pulsed Doppler ultrasound. The augmentation in mean $Q$ is produced by a marked increase in the diastolic flow component rather than by the comparatively moderate increase in the systolic wave. The descent of the flow wave decays from the peak, exhibiting an exponential slope throughout the whole diastole. This characteristic change is described in a series of papers concerning the mechanism of pulse wave formation (Busse et al., 1975). $Q_{\mathrm{min}}$ is shifted from the early diastole to the foot-point of the subsequent systolic wave and usually shows positive values (Fig. 2, Table 1). Recent micromanometric (Bollinger et al., 1976) and noninvasive measurements (Mahler et al., 1976) of distal arterial pressure confirmed the notion of sizeable pressure gradients arising during systole as well as diastole along the arteries of the limbs during reactive hyperaemia. According to the theory (Wetterer, 1968), the direction of the second wave in the pulsatile flow tracing is dependent on the ratio between reflecting resistance and flow resistance. At rest, the reflecting resistance exceeds the flow resistance, and the second flow wave in early diastole results as negative. During PORH, the reflecting resistance decreases drastically, reversing the negative direction of the second component. The same alteration in the diastolic flow curve was observed downstream of arterial occlusions or stenoses, where the resistance is high in the collaterals, but minimal distally (Brunner et al., 1974).

The fundamental pharmacological action of the nitrites is a relaxing effect on smooth muscle of the vessels (Goodman and Gilman, 1970). Inhalation of amyl nitrite produced an increase of the positive as well as of the negative flow components of the pulsatile flow in the femoral artery, and hereby an increase in $\Delta \mathbf{Q}$. The phasic flow tracings exhibit a biphasic appearance, while the diastolic forward flow wave is abolished. Application of atropine shows that an increase in heart rate alone does not induce the same changes in the pattern of the flow wave with regard to the second component as does amyl nitrite (Fig. 2). The responses to amyl nitrite in mean $\mathbf{Q}$ are inconsistent, but correspond in the average to the decreasing flow values shown in earlier plethysmographic measurements (Delius and Enghoff, 1970). The lack of increase in mean $Q$ in spite of accelerated heart rate is explained by the fact that the change to the negative side exceeds the change to the positive one. In another study, using pulsed Doppler ultrasound, similar effects on pulsatile as well as on mean femoral flow were shown after intravenous injection of isosorbid dinitrate (Bollinger et al., in press). A biphasic pattern, caused by loss of the positive diastolic flow wave as induced by amyl nitrate, is observed after intravenous application of xanthinol nicotinate, another substance with dilating action on peripheral vasculature (Goodman and Gilman, 1970). However, the size of the negative 
wave decreases in contrast to the effect induced by former drug, while the positive component is augmented and $\Delta Q$ remained constant. Therefore, this compound induces a marked increase in mean $Q$, although heart rate is less accelerated than after amyl nitrite. The divergent responses in mean $Q$ to amyl nitrite and xanthinol nicotinate, both of them being vasodilators, may be related to a regionally different action of these 2 drugs on the arterial resistance (Delius and Enghoff, 1970). While xanthinol nicotinate may mainly dilate the arteries of the extremities, the main action of amyl nitrite may be restricted to vessels of areas other than the lower limbs. Another explanation for the lack of a consistent increase in mean $Q$ may be seen in the marked drop in systemic blood pressure induced by amyl nitrite, which reduces perfusion pressure to the limb. After xanthinol nicotinate, blood pressure remains unaltered probably because of the slower onset of action of this drug. It allows for a more complete compensation of systemic pressure by reflex mechanisms, involving mainly a secondary increase in venous tone and in the contractile force of the heart (Mason and Braunwald, 1965; Mason et al., 1971).

On the other hand, mild elevation of systemic blood pressure by infusion of angiotensin amide was associated by a shift of the phasic flow curve upward from the zero line, p oducing sustained forward flow during the whole diastole. However, the formal appearance of the pulse contour was little changed from resting state with regard to the second and the third flow wave components and $\Delta \dot{Q}$. In spite of slowing the heart rate, mean $\dot{Q}$ was increased markedly. Treatment of patients with arterial occlusive disease by pharmacologically induced mild hypertension has been in clinical use for several years (Dahn et al., 1969; Hansteen and Lorentsen, 1972). The present data show that hypertensive interventions in certain ranges augment femoral artery flow not only in these patients, but also in normal subjects. This effect is probably produced because the increasing effect of vascular resistance in other regions ( $\mathrm{eg}$ in the splanchnic bed) exceeds that in the lower limbs.

The various interventions described in the present study affect the diastolic flow phase of the pulsatile femoral artery more than the systolic component (Fig. 6). Diastole covers a proportionately long time period of the cardiac cycle during which variations in either positive or negative direction are strongly effective on the average flow volume. Unlike systolic flow velocity, reaching its upper limits by the twofold increase in PORH, set by frictional forces in turbulent flow (Withmore, 1968), total diastolic flow may vary within a wide range from negative to positive values. Thus, diastole may be regarded as

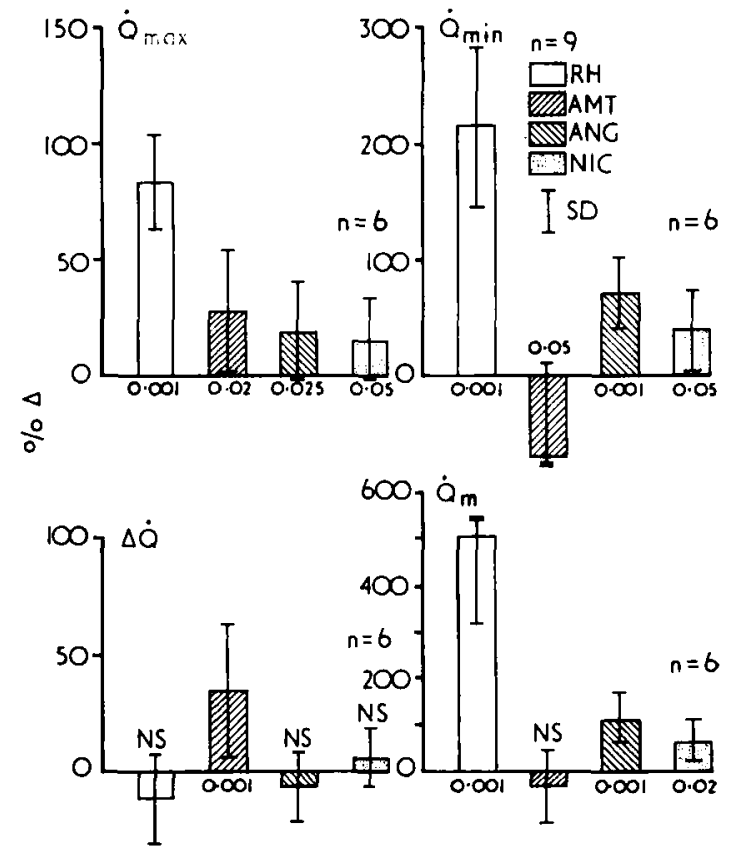

Fig. 6 Percentage change ( $\% \Delta)$ from control values in maximum $\left(\dot{Q}_{\max }\right)$, minimum $\left(\dot{Q}_{\min }\right)$, mean flow $\left(\dot{Q}_{m}\right)$, and the flow pulse amplitude $(\Delta Q)$ in common femoral artery of 9 normal subjects induced by 4 interventions: $\mathrm{RH}=$ postocclusive reactive hyperaemia; $A M T=a m y l$ nitrite inhalation; $A N G=$ angiotensin amide infusion; $N I C=$ xanthinol nicotinate injection. Numbers next to bars indicate significance levels; $N S=$ not significant.

a temporal reserve for additional forward flow to cover increased peripheral demands. This flow reserve is mobilised by creating an increase in pressure gradient from the centre to the periphery of the circulation either by dilatation of the distal arteries or by increasing central perfusion pressure.

\section{Synopsis}

Blood flow was measured transcutaneously in the common femoral artery of 9 healthy subjects using a multi-channel pulsed Doppler ultrasound flowmeter. This device allows quantitative measurement of pulsatile and mean flow volume. At rest, the pulsatile tracings showed systolic flow maxima $\left(Q_{\max }\right)$ of $25.6 \pm 13.6 \mathrm{~cm}^{3} / \mathrm{s}$, followed by flow minima in the early diastole in the reverse direction of $-11.0+4.6 \mathrm{~cm}^{3} / \mathrm{s}$, diastolic forward flow waves of $25 \pm 12 \%$ of $Q_{\max }$, and mean flow (Q) of $4.4 \pm$ $1.9 \mathrm{~cm}^{3} / \mathrm{s}$. The pattern of the resting pulsatile flow was influenced characteristically by different acute 
interventions. During postocclusive reactive hyperaemia, $Q_{\max }$ was increased by $84 \pm 20 \%$ of the control values, the reverse flow wave disappeared and mean $Q$ increased to a maximum of $505 \pm 186 \%$ (all $\mathbf{P}<0.001$ ). Inhalation of amyl nitrite, producing tachycardia, and a significant drop in systemic blood pressure (BP), augmented $\dot{Q}_{\max }$, but diminished $Q_{\min }$ and the diastolic forward flow. The flow pulse amplitude $\left(Q_{\max }-Q_{\mathrm{m} 1 \mathrm{n}}=\Delta \mathbf{Q}\right)$ was widened by $35 \pm 28 \%(P<0.001)$, while mean $Q$ did not exhibit a significant change. Mild elevation of BP by angiotensin amide led to a shift of the pulsatile flow curve upward from the baseline without changes in the shape of the flow pulse and in $\Delta Q$. Intravenous application of xanthinol nicotinate was associated with an increase in $\dot{Q}_{\max }, \dot{Q}_{\min }$, and mean $\dot{Q}$, although the diastolic forward flow wave was diminished. In all of these interventions the mean $\mathbf{Q}$ was influenced most by alterations during the diastolic phase of the pulsatile flow.

\section{References}

Bernstein, E. F., Murphy, A. E., Jr, Shea, M. A., and Housman, L. B. (1970). Experimental and clinical experience with transcutaneous Doppler ultrasonic flowmeters. Archives of Surgery, 101, 21-25.

Bollinger, A. (1969). Durchblutungsmessungen in der klinischen Angiologie. H. Huber: Bern.

Bollinger, A., Barras, J. P., and Mahler, F. (1976). Measurement of foot artery blood pressure by direct atraumatic micromanometry in normal subjects and in patients with arterial occlusive disease. Circulation, 53, 506-512.

Bollinger, A., Fromm, U., Brunner, H. H., Mahler, F. Casty, M., Anliker, M., and Siegenthaler, W. (1975). Die Wirkung von Isosorbid-Dinitrat (ISD) auf den peripheren Kreislauf: Eine Studie mit kontinuierlicher perkutaner Flussmessung in der A. femoralis. Nitrat-Symposium 1975 Stockholm (In press).

Brunner, H. H., Bollinger, A., Anliker, M., Zweifel, H. J., and Rutishauser, W. (1974). Bestimmung instantaner Strömungsgeschwindigkeitsprofile in der A. femoralis communis mit gepulstem Doppler-Ultraschall bei Stenosen und Verschlüssen der Beckenarterien. Deutsche Medizinische Wochenschrift, 99, 3-7.

Busse, R., Wetterer, E., Bauer, R. D., Pasch, T., and Summa, $J$. (1975). The genesis of the pulse contours of the distal leg arteries in man. Pfïgers Archiv, 360, 63-79.

Dahn, I., Halböök, T., Larsen, O. A., Lassen, N. A., Nilsen, N. R., and Westling, H. (1969). Treatment of acute ischemic pain in the leg by induced hypertension. Acta Chirur gica Scandinavica, 135, 391-394.

Delius, W., and Enghoff, E. (1970). Studies of the central and peripheral hemocynamic effects of amyl nitrite in patients with aortic insufficiency. Circulation, 42, 787-796.
Doriot, P. A., Casty, M., Milakara, B., Anliker, M., Bollinger, A., and Siegenthaler, W. (1975). Quantitative analysis of flow conditions in simulated vessels and larger human arteries and veins by means of ultrasound. Proceedings 2nd European Congress on Ultrasonics in Medicine, Munich. $160-168$.

Fronek, A., Johansen, K., Dilley, R. B., and Bernstein, E. F. (1973a). Ultrasonographically monitored postocclusive reactive hyperemia in the diagnosis of peripheral arterial occlusive disease. Circulation, 48, 149-152.

Fronek, A., Johansen, K. H., Dilley, R. B., and Bernstein, E. F. (1973b). Non-invasive physiologic tests in the diagnosis and characterization of peripheral arterial occlusive disease. American Journal of Surgery, 126, 205.

Goodman, L. S., and Gilman, A. (Editors) (1970). The pharmacological basis of therapeutics. 4th edition. Macmillan: London, Toronto.

Hansteen, V., and Lorentsen, E. (1972). Induced hypertension in the treatment of severe ischaemia of the foot. Circulation, 46, 976-982.

Hillestad, L. K. (1963). The peripheral blood flow in intermittent claudication. V. Plethysmographic studies. The significance of the calf blood flow at rest and in response to timed arrest of the circulation. Acta Medica Scandinavica, 174, 24.

Mahler, F., Koen, L., Johansen, K., Fronek, A., and Bernstein, E. F. (1976). Post-occlusive and post-exercise blood flow velocity and ankle pressure in normals and marathon runners. Angiology, 27, 721-729.

Mason, D. T., and Braunwald, E. (1965). The effects of nitroglycerin and amyl nitrite on arteriolar and venous tone in human forearm. Circulation, 32, 755-766.

Mason, D. T., Zelis, R., and Amsterdam, E. A. (1971) Actions of the nitrites on the peripheral circulation and myocardial oxygen consumption: Significance in the relief of angina pectoris. Chest, 59, 296-305.

McLeod, F. D. (1974). Multichannel pulse Doppler techniques. In Cardiovascular application of ultrasound. North-Holland Publishers: Amsterdam.

Rutishauser, W., Brunner, H. H., Bollinger, A., Brandestini, M., Doriot, P. A., and Anliker, M. (1974). Blutflussmessung in Arterien aus instantanen Strömungsprofilen mit gepulstem Doppler-Ultraschall. Verhandlungen der Deutschen Gesellschaft für Kreislaufforschung, 40, 149-153.

Strandness, D. E., Jr, McCutcheon, E. P., and Rushmer. R. F. (1966). Application of a transcutaneous Doppler flowmeter in evaluation of occlusive arterial disease. Surgery Gynecology and Obstetrics, 122, 1039-1045.

Wetterer, E., and Kenner, T. (1968). Dynamik des Arterienpulses. Springer: Berlin.

Whelan, R. F. (1967). Control of the peripheral circulation in man. Charles C. Thomas Publisher: Springfield, Ill., USA.

Withmore, R. L. (1968). Rheology of the circulation. Pergamon Press: Oxford

Yao, J. S. T., and Bergan, J. J. (1974). Application of ultrasound to arterial and venous diagnosis. Surgical Clinics of North America, 54, 23-38.

Zelis, R., and Mason, D. T. (1970). Mechanism of systemic hemodynamic response during limb reactive hyperemia. American Journal of Physiology, 217, 1742-1746. 